\title{
Design education oriented to nature
}

\author{
B. Colombo ${ }^{1}$, F. Rosa ${ }^{2}$, E. Rovida $^{2}$ \& R. Viganò ${ }^{2}$ \\ ${ }^{1}$ INDACO Department, Politecnico di Milano, Italy \\ ${ }^{2}$ Mechanical Engineering Department, Politecnico di Milano, Italy
}

\begin{abstract}
Nature is a starting point to analyse and to conceive solutions for complex systems, and a reservoir of inspiration to provide innovative answers to the product development as well as to the interaction between man and nature: this is the first key idea that the authors would like to transmit to the new generations of engineers and designers. Furthermore, it is also important to embed the development of technology within a sustainable development frame-work: from this point of view the authors are encouraging students to develop a particular case-study.
\end{abstract}

Keywords: design education, TRIZ, theory of technical systems, bionics.

\section{Introduction}

A not thorough analysis could lead to the conclusion that the technical university curricula should be focused only on technical matters; on the contrary, a deeper analysis about what a good technician should know reveals that several other aspects are relevant. In this paper we will mainly deal with two of these aspects. First, we want to highlight the importance to recognize, among the dozens of mathematical models that a young engineer knows, the model that better represents the specific physical problem, as to say the ability to analyze the natural phenomenon and to "extract" its "governing law". Second, a good engineer should not merely repeat by rote something that he learned when he was a student, but should also be able to develop new ideas and products, and even to design a new machine, even starting from some generic functional requirements.

Several theories and methods have been developed to help the designers to perform the latter activity; among these procedures and approaches we are particularly interested in the possibility to use the forms and laws of nature as a 
source of inspiration and a model for the design. Nature is then both a starting point to analyse and to conceive solutions for complex systems, and a reservoir of inspiration to provide innovative answers to the product development as well as to the relationship between man and nature. This field, known as Bionics, regards the application of methods and systems, found in nature, to engineering and technology, and relies on the consideration that nature, through billions of years of trial and error, has produced effective solutions for a wide variety of complex problems. A deeper comprehension of natural mechanism could then be a valuable help for engineers' work and, therefore, should be included in their curricula. In this paper a couple of didactic experience of the authors will be described. One of these experience is a course held (by one of the authors) at the Industrial Engineering Faculty of the Politecnico di Milano and specifically oriented to design methods and theories; the authors are working to include Bionics basic concepts within the syllabus of this course, also on the basis of another author experience, who attended the other course, held at the Aalborg University in Denmark.

\section{Objectives}

The aim of this paper is to describe a couple of didactic experiences of the authors, based on the above developed considerations, and then to critically analyze this experience, to propose some developments.

In other words, in the following we will describe a first attempt to introduce more "nature" in the mechanical engineering students" education, with the aim to show them how to design products taking into account not only the mandatory rules on pollution and recycling (for example), but also the fundamental requirements (sustainable development) and suggestions (Bionics) of the Nature itself.

\section{Methods}

The following brief definitions of design, education and nature have been used as starting point to develop and integrate the basic concepts of Bionics in the above mentioned course:

- Design: the elaboration of all the information necessary to realize a product, from the first idea, to the definition of all the constructive information;

- Education: the transmission of information, professional skills and know-how. This transmission needs to be accurately planned and prepared, taking into account the theories of technical communication;

- Nature: the astrophysical, geophysical and biological world.

The authors' key idea is to embed Bionics basic concepts in a previously developed logical schema for the development of products derived from [1-3]. This schema has been conceived merging the two following approaches:

- Theory of Technical Systems (TTS) that proposes principles and constructive solutions to perform a given function; 
- Design for $X(\boldsymbol{D} \boldsymbol{X} X)$, that takes into account that a given product must behave satisfactorily in all the phases of its life cycle. From these considerations the engineer can derive the criteria to compare many products that perform the same function, or to upgrade the behavior of an existing product.

Briefly, the Theory of Technical Systems, starting from a given function, after an analysis finalized to point out the component functions, proposes the "best" principles and constructive solutions, extracting them from previously built database.

Sources of principles and constructive solutions could be then subdivided in two main categories:

- Known: state of the art, historical heritage, patents...

- New: heuristic methods, TRIZ, creativity ...

The criterion adopted to establish the "best principle" is that the selected principles and constructive solutions have to behave satisfactorily in all phases of the whole life cycle of the product (fig. 1).

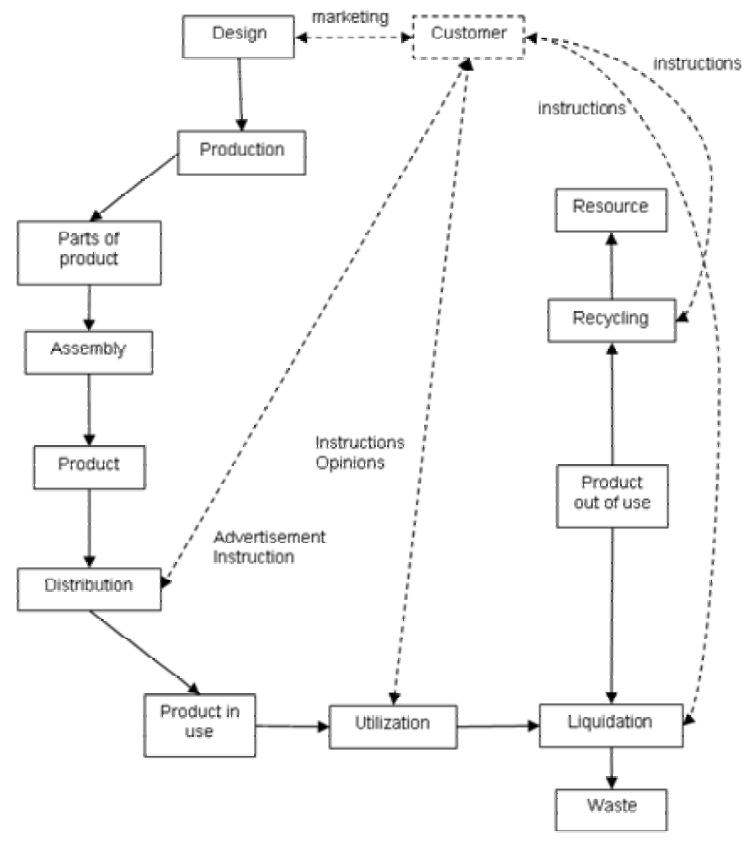

Figure 1: $\quad$ Schema of the product life-cycle.

The Design for $X$ is the approach used as a basis to conceive a method to evaluate the behavior of the product in all the phases of the life cycle: this evaluation can also be useful for the comparison of many products, as well as to upgrade a given product in some specific phases, using, for example, "design rules" oriented to the specific phase. 
The authors have considered three possibilities to establish a connection between Nature and Design (at least, within a didactic environment):

- Observation of the nature as source of new ideas.

- Avoidance or minimization of damages to the environment (intended as complex of astrophysical, geophysical and biological world, including men). The $D f X$ based design approaches known as Design for Environment and Design for Safety allows taking into account these requirements.

- The application of these methods to design and realize product oriented to the environment protection, e.g. a device for waste collection.

\section{Observation of nature as source of new ideas}

In the process towards product innovation designers can use all the knowledge that they can found in history and culture. In this research we have considered a wide variety of methods and tools, assessed according to their applicability, limits, objectives and advantages - high availability of information, good structuring degree, easy of application. The authors have focused their attention on tools and methods for producing innovation based on analogy; within this field, the authors are developing the idea of embedding the observation of natural phenomena in the TTS approach as a source of innovative solutions, increasing the amount of solutions and principles available from the other entire well know sources.

Today, "analogy" means a "relationship of similarity between some constitutive elements of two facts or objects, which allows you to mentally deduce a certain degree of likeness between the facts and objects themselves" [9]. Actually, the word "analogy" comes from the Greek analoghia ( $\alpha v \alpha \lambda o \gamma \iota \alpha)$. Its origins are very ancient and founded upon the mathematical concept of "proportion" ( $a: b=c: d)$, that establishes a similarity of ratios.

The analogy process is a tool used for elaborating new theories, scenarios and ideas in sciences, art, architecture and design. In particular the use of analogy is evident in the applied arts. An example of use of analogy within architecture and design is biological analogy, as to say an analogy between living organisms and man-made articles. In the field of design and product development, through the process of analogy, it is possible to further develop consolidated products, transferring to them innovations coming from specific and extremely advanced sectors.

If the use of analogies is not accidental, but is designed to meet specific demands for improved/renewed lifestyles, the consequent innovation becomes effective. In this way the innovation process does not have to rely on invention but can simply become a technical and cultural interpretation of something that already exists [10].

Analogy is the basic principle on which the study of nature as a source of innovative ideas is based. This study is usually known as: bionic (from biology and technology), or bionick (from biology and technik that in German means technology), or biomimetic (from biology and mimesis ( $\mu \mu \eta \sigma \eta \varsigma$ ) that, in ancient 
Greek, means imitation). Bionic is mainly devoted to find out the characteristics of living organisms that could be useful to develop methods for developing or even for planning the development, of industrial products [5-8].

The observation of Nature is a source of innovation, since it could allow transforming the study and the analysis of natural elements into an innovative product. Nature, in fact, is an inexhaustible source of ideas and inspiration from which many disciplines can obtain benefit.

It is also worth noting that, in general, in the professional life, the borders among different disciplines are commonly crossed: this means that students' knowledge has to be interdisciplinary and implies that research groups of different scientific fields have to cooperate and to establish direct connections among the respective fields. This requirement is particularly true in the Bionic design field, where competencies coming from very far field are required. On the other hand, introducing the study of Nature in technical universities' curricula would require a big effort, but the results that could derive from this kind of cooperation could largely repay such an effort.

There are several approaches to investigate the various sources of Bionic knowledge: from the intuitive creativeness to the systematic search, from the formal search to the solutions by analogy.

Our approach to teaching Bionics design is based on building the designer's ability to observe the natural phenomena, paying attention not only to the natural shapes, but also to the mechanical and morphological features. These features, for example, are of great importance in systems where the realization of products must take into account new materials and structures that have to be both economically advantageous and environmentally friendly.

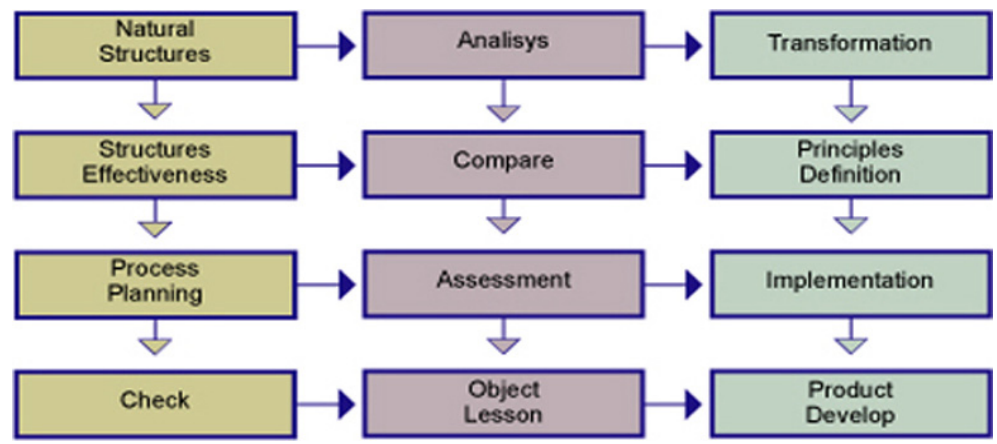

Figure 2: Diagram of the process from analysis of natural structure up to product development.

Apart from the tools and processes employed it is important to underline the new "project approach" provided by Bionics: a new way to deal with the project in the mutable reality of today's market. The purpose is to reach a new level of knowledge and to implement a method that can innovate the product development process in the educational field (fig. 2). 


\section{Applications and results}

\subsection{Bionic}

In this section the application of the above described approach to Bionics at the Architecture and Design Department of Aalborg University in Denmark will be described. This methodology is used in a mini project during a course of the $4^{\text {th }}$ semester, that has engineering characteristics and it is oriented to product development. Bionics is a useful tool able and allows students to acquire basic knowledge.

The concepts explained above, illustrated through case studies, are organized in the phases of observation, analysis and transformation of natural shapes into new products and industrial systems.

\subsubsection{Phase 1 - analysis. Hands-on session}

In this part the students choose and analyze an object or a natural product. First observing the objects with the naked eye, the students make sketches and take some notes. After, it is sectioned so that the inside structure could be examined, and then observed through a microscope. In addiction to sketches and notes digital photos are used to record and later analyze the characteristics and structure of the object under study. The aim of this first phase is to understand "what", "why", "how" and to understand the object's shape, structure, and functional principles (fig. 3) [11].

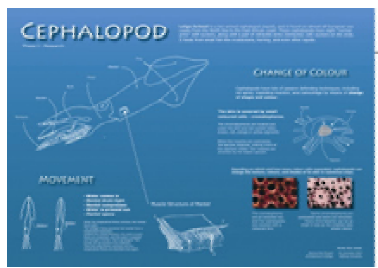

Figure 3: $\quad$ Phase 1: analysis.

\subsubsection{Phase 2 - transformation}

The scope of the second part is the definition of principles. The students operate a selection of the information collected. The first step consists in defining the project focus, as to say the students have to focus their attention, in a unique and original way, on a characteristic element of the object. The aim is to extrapolate mathematical, geometrical and structural principles by means of a process of abstraction and simplification, in order to fully understand how the object works. This is done, for example, performing some mechanical resistance tests, the results of which are then embedded in three-dimensional models, in order to fully understand how these principles work and if all the procedure has been executed correctly. In this phase it is not always possible to come to definitive conclusions, but through practical analysis a student can even infer some elements that will also be useful in other fields of research (fig. 4). 

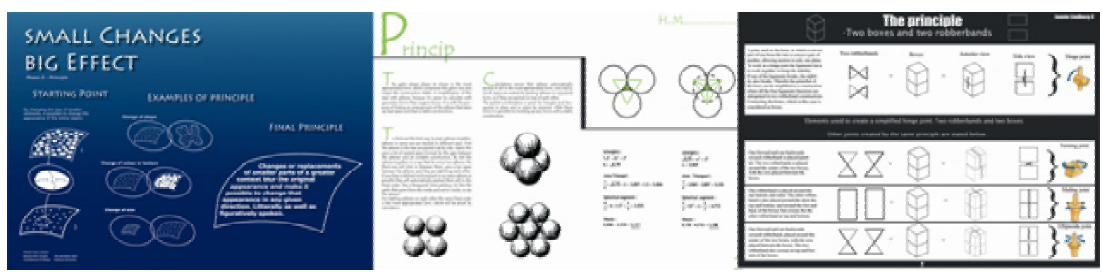

Figure 4: Phase 2: transformation.

\subsubsection{Phase 3 - implementation}

The aim of this stage is to implement principles found in the analysis of natural objects and elements in the development of a new design. This shows how Nature can be a valuable source of inspiration for design in terms of construction, form and function (fig. 5).
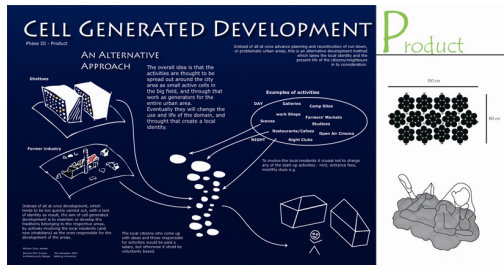

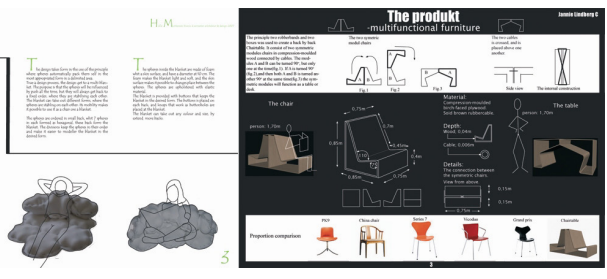

Figure 5: $\quad$ Phase 3: implementation.

Within this context, the learning of Bionics design is then founded on the concept of active learning that implies that students have to learn making exercises, experimenting and studying concrete problems.

\subsection{Avoidance or minimization of damages}

This problem is present in all the life cycle of the product (fig. 1), since all its phases require the use of energy and materials and could require the use of substances dangerous for the environment.

The general phases of the life cycle are distribution, utilization and liquidation. These phases can be analyzed more in detail to highlight the specific phases:

- Distribution: Packaging, Charging, Transportation, Discharging

- Utilization: Behaviour, Maintenance, Ergonomics, Safety, Reliability, Aesthetics

- Liquidation: Reuse, Reconditioning, Reutilizing, Recycling, Elimination

Each phase can then be analyzed from the points of view of some requirements: simplicity, efficiency, safety, sustainability, economy.

Evaluating each phase from the point of view of the above mentioned requirements, it is possible to highlight the "aspects" that characterize the phase. 
As an example, the specific phase "reuse" (the new utilization of the product without modifications and only with the most necessary repairs) can be analyzed in the following aspects:

- Simplicity: easy of essential repairs, of maintenance ...

- Efficiency: easy of essential repairs, of maintenance ...

- Safety: reliable design

- Sustainability: no contaminating operations or substances in essential repairs, in maintenance, ..., exclusion of pollution through reuse of the product, and exclusion of excessive energy consumption by the reuse of the product

- Economy: easy of essential repairs, of maintenance, ..., and exclusion of excessive maintenance costs by the reuse of the product

These aspects can be used to evaluate and compare some given products and to upgrade the behaviour of an existing product.

\subsection{Design of machines and product for environment}

The nature and the environment are, of course, of great importance: the conservation of nature is equivalent to the conservation of humanity, since it is a part of nature itself. Furthermore, it is obvious that if we want to use of Nature as a source of new ideas, Nature must exist and also its variety must be conserved.

On the other hand, Nature conservation can not be reached returning to the stone age, as someone could wish, but has to be achieved by means of a technical development that takes into account also Nature conservation, in other words, by means of a sustainable development.

Design Methodologies are important tools to develop both sustainable and technical products the function of which would be environment preservation.

As an example of a product, the general function of which is "Preserve Environment", the general function "Collect, load, transport and discharge the solid waste" [13]. A function analysis highlighted the following component functions:

- Main functions: Waste collection (hold the waste in an appropriate storage place), Waste loading (waste loading and stocking on a transportation mean), Waste transportation, and Waste unloading (waste unloading and stocking, incineration, ...)

- Internal and External interactions: Positioning of the system with respect to the waste to be loaded, Movement (waste transport to the dump), and Unloading of the waste

In order to accomplish each of this sub-functions and interactions, interface, clamping, lifting, rotation, opening and (re) positioning sub-systems have been studied, so that it has possible to define the principles useful to perform each of the component function. The synthesis of these principles has then been investigated, and, finally, a waste system design proposals described.

As an example, the solution developed for the first two main functions (waste collection and storage) will be briefly presented. 
Since the main goal is to reduce the impact of the waste on the urban environment, paying particular attention to the waste separation for the recycling, the reduction of the time necessary to store the waste, and to make the waste storage less visible as possible, the storage place (from where waste will be collected and transported to the dump) could be one of the following: a tube in the buildings that conveys the waste in an underground well; waste containers well integrated with the surrounding urban environment; waste containers with waste compression systems; a system of tube (similar to the sewer system) that convey also solid waste; multi-function transportation means, that can collect and separate different kind of waste at the same time, reducing the time of the operation. The third solution (waste containers) has been selected and developed, conceiving the storage system shown in fig. 6 . This system has been conceived taking also into account that it would be a part of a more complex urban waste collection system that begins in each home and ends in a dump.

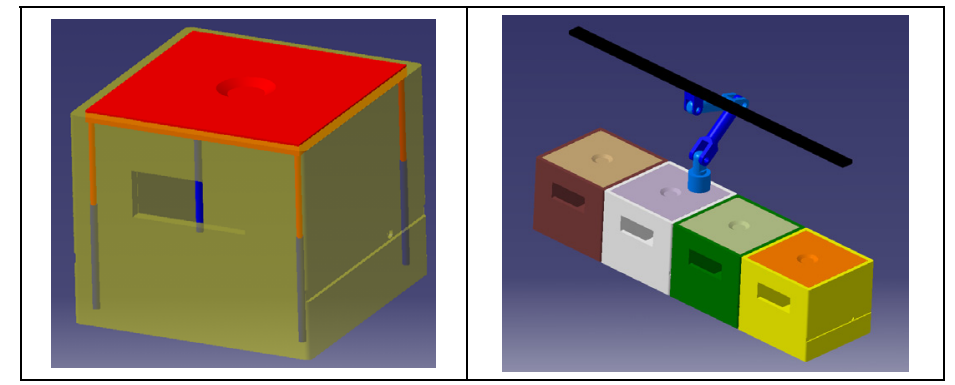

Figure 6: Storage system.

\section{Conclusions}

In authors' opinion, Bionics design is an appealing subject, since Nature observation could be very well embedded within several design methods and product development process. In fact, several aspects of natural objects are appealing from an engineering point of view: lightness, elegance, strength...

In order to further proceed in this direction, the interdisciplinary knowledge of engineers has to be developed.

All the above discussed and developed concepts have been introduced in the course "Design Methods", held by one of the authors at the Industrial Engineering Faculty of the Politecnico di Milano.

In this course, the students utilize all the above introduced methods to develop innovative products able to perform any given function.

The success of this course is encouraging: the students work with great interest and, sometime, with enthusiasm, learning to recognize and manage the interactions between the technical aspects and the nature.

Furthermore, they are addressed toward the conception of a sustainable development, since, the authors firmly believe that the nature is a wide and valid source of new ideas, and, then has must be preserved. 


\section{References}

[1] Rodenacker, W.G., Methodisches Konstruieren, Springer-Verlag: Berlin and New York, 1970.

[2] Hubka, V., Theorie der Konstruktionsprozesse, Springer-Verlag: Berlin and New York, 1973.

[3] Pahl, G., Beitz, W., Feldhusen, J., Grote, K.-H., Engineering Design: A Systematic Approach, 3rd ed., 2007, ISBN: 978-1-84628-318-5.

[4] Matthek, C., Design in Nature. Learning from Trees. Springer, 1997.

[5] Fukuoka, Y., Kimura, H. \& Cohen, A.H., Adaptive dynamic walking of a quadruped robot on irregular terrain based on biological concepts. The International Journal of Robotics Research, 22(3-4), 2003.

[6] Bandyopadhyay, P.R., Trends in biorobotic autonomous undersea vehicles. IEEE Journal of Oceanic Engineering, 30(1), 2005.

[7] Delcomyn, F., Walking robots and the central and peripheral control of locomotion in insects. Autonomous Robot - Kluwer Academic Publisher, Netherlands, 7, pp. 259-270, 1999.

[8] Sfakiotakis, M., Lane, D.M. \& Davies, J.B.C., Review of fish swimming modes for aquatic locomotion. IEEE Journal of Oceanic Engineering, 24(12), 1999.

[9] Devoto, G., Oli, G.C., Il dizionario della lingua italiana, Firenze, 1990.

[10] Ingaramo M. O., Hard design. Il product design oggi tra innovazione e competitività, Aracne, Roma, 2005.

[11] Stokholm, M. Bionics. Students guide for mini project on 4th term 2006, Aalborg: Aalborg University, Architecture \& design, 2006

[12] Penati, A., Giovane è il Design: nodi contemporanei della didattica per il progetto. Milano, Edizioni POLI.design, 2002

[13] Rosa, F., Rovida, E., Poletti, G., Reffo, A., Tassan, G., Tiberti, S., Trezzi, A., Application Of Methodic Design To The Concept Design Of A Solid Waste Collection System, $12^{\mathrm{th}}$ Annual International Sustainable Development Research Conference, April 6-8, 2006 - Hong Kong 